\title{
Physical Effects of Pre-hydrolysis and Alkali Treatment of Empty Fruit Bunch (EFB) Fibers
}

\author{
Mohammad Aliff Shakir, Mohd Firdaus Yhaya, and Mardiana Idayu Ahmad
}

\begin{abstract}
This study focused on the physical effects of pre-hydrolysis and alkali treatment of empty fruit bunch (EFB) fibers collected from one of oil palm industry in Penang Malaysia. The pre-hydrolysis times used were $20 \mathrm{~min}, \mathbf{4 0} \mathrm{min}$, $60 \mathrm{~min}$, and $80 \mathrm{~min}$. While for alkali treatment, duration of 2 hours was applied by using $17 \%, 22 \%, 27 \%$ and $32 \%$ of sodium hydroxide (NaOH) treatment. From this study it was found that the amount of extractives being removed was increased with the increasing of time, while the hemicellulose content was decreased. In addition, lignin content was reduced when high concentration of alkali charge was used. Moreover, the longer the pre-hydrolysis time, the greater the loss of hemicellulose, which subsequently increased the size of capillary. Also, gradual removal of lignin during the pulping process caused reduction of fiber length and pore structures in the fibers. Thus it can be said, from this study continuous treatment (pre-hydrolysis and alkali treatment) was found to increase the performance of the fibers up to a certain limit before declining.
\end{abstract}

Index Terms-Pre-hydrolysis, alkali treatment, empty fruit bunch fibers, hemicellulose, lignin.

\section{INTRODUCTION}

Oil palm is one of the important productions which was introduced to Southeast Asia such as Malaysia and Indonesia by European traders in the early $19^{\text {th }}$ century [1]. The production of oil palm in this region has helped to change its agriculture and economy scenarios [2]. In this production, huge amount of biomass waste [3] in the form of empty fruit bunches (EFBs), oil palm trunks (OPT), oil palm fronds (OPFs), palm pressed fibers (PPFs) and palm shells are produced [4]. EFBs are available in abundance as fibrous material in which there is 230-250kg EFBs in $1000 \mathrm{~kg}$ of freshly fruit bunch. EFBs consist of 41.3-45\% cellulose, 25.3-33.8\% hemicellulose, and 27.6-32.5\% lignin [3], [5]. From this, we can see that the most significant material in EFBs is cellulose, which has gained great interest amongst researchers and industries. This material can be converted into value-added products and other potential applications in chemical, food, and composite industries.

Cellulose is an abundant biopolymer which formed by the combination of multiple glucose monomer at $\beta$ - 1 , 4 glycosidic bond [1]. Cellulose can be found as intertwined microfibrils in the cell wall of plants to reinforce the plant by giving mechanical strength [2]-[4]. It has 39\% of amorphous

Manuscript received August 15, 2017; revised November 15, 2017.

Mohammad Aliff Shakir, Mohd Firdaus Yhaya, and Mardiana Idayu Ahmad are with the Universiti Sains Malaysia, Malaysia (e-mail: \{alip6001, laxmia707,drmia707\}@gmail.com). structure that may contribute to water absorption and 61\% crystalline structure [5]. The drawback of using cellulose in order to isolated crystalline region usually using acid hydrolysis in order to remove amorphous region [6], [7]. Hemicellulose is a combination of many types of cycled saccharides such as xylose, mannose, and glucose. It consists a highly branched random structure which mainly from amorphous region [3]. Hemicellulose is soluble in hot water and attached to cellulose by hydrogen bond. So, by removing hemicellulose, it may cause physical changes of fibers which led the fiber to have less dense and rigidness that will influence moisture absorption [8].

Lignin is formed by a repeating unit of phenyl-propane units from an amorphous region consisting of aromatic units such as guaiacyl, syringyl and phenylpropane [3]. The lignin behavior during any chemical treatment could not be easily accessed or degraded due to the presence of strong carbon-carbon linkages and other chemical groups such as aromatic groups [12]. Thus lignin acts as a matrix of a fiber material which connects cellulose and hemicellulose together [9], [10]. Thus, by removing the lignin, blockage will be discarded and would produce higher pore structures in fiber. This factor also will allow water molecule to transfer in short time with less resistance.

Due to the important roles of these substances, many analyses are conducted in the efforts to convert EFB fibers into value-added products. Previous research reported that, the high purity unbleached cellulose pulp could be obtained from EFB via pre-hydrolysis treatment and soda pulping [11]. Pre-hydrolysis is a water treatment process that usually applied before pulping process. The mechanism involves steam power, where the fibers is pressurized at high pressure and high temperature in digester. At this point, hemicellulose in the fibers will be hydrolyzed, lignin will be modified, increasing access to surface area, decreasing the crystallinity of the cellulose and its degree of polymerization [12], [13]. For lignin removal, the process will take place during pulping process. Pulping process involves alkali treatment where the lignin would be extracted from the fibers. There are few pulping methods to remove lignin in fibers such as mechanical pulping and chemical pulping. Mechanical pulping uses mechanical force in order to separate and break bonding between fibers until they fragment. So, the main objective of mechanical pulping is to maintain some part of lignin in order to achieve high yield production. However, mechanical pulping has low aging resistance where it has a tendency to discolor. Meanwhile chemical pulping uses alkali treatment 
such as sodium hydroxide and sodium sulphite. In this process, the fiber is cooked in digester at high temperature and high pressure. This is intended to dissolve the lignin. In this treatment, the usage of higher concentration of alkali treatment will result in more lignin to be removed. However, it might cause cellulose degradation which will shorten the fiber length. By comparing both method, chemical pulping able to give better quality in optical and mechanical properties compared to mechanical pulping [14].

Removing hemicellulose through pre-hydrolysis contributes to enlarge capillary spaces in the fiber. It helps to improve the capillary action of fiber during water absorption. Capillary action is an ability of a fluid to flow in narrow spaces without any external assistance forces. In order to achieved equilibrium balance, the capillary action able to lift up and transfer the liquid into material even against gravity [15]. The speed of absorption and the forces for lifting the liquid against gravity are depending on the diameter of capillary [16], [17]. Previous study showed that the chemical composition such as hemicellulose and lignin affected the diameter of capillary and porosity of the fiber [8]. Throughout the lietrature, it can be seen that the understanding of chemical composition helps to improve fibers for future application. Thus, this work was performed to study the chemical composition of EFB fibers using pre-hydrolysis and alkali treatment. Data from this study would be useful in the determination of optimum chemical compositions in the EFB fibers that will affect the swelling properties of these fibers.

\section{MAterial AND MethodS}

\section{A. Empty Fruit Bunch Fiber (EFB) Preparation}

In this study, EFB fibers collected from one of oil palm industry in Penang Malaysia were used. Two types of chemical treatments were used in terms of: i) time for pre-hydrolysis and; ii) alkali treatment during the pulping process. The pre-hydrolysis time used was $20 \mathrm{~min}, 40 \mathrm{~min}, 60$ min and $80 \mathrm{~min}$. A duration of 2 hours was applied by using $17 \%, 22 \%, 27 \%$ and $32 \%$ of sodium hydroxide $(\mathrm{NaOH})$ for alkali treatment. The chemical composition of EFB fibers after the chemical treatments was determined by using a few methods. Extraction method was used to remove extractives by following TAPPI T204 om-88 procedure. In order to determine hemicellulose content in EFB fibers, methods from Wise et al. and TAPPI T 203 om-93 procedure were applied [18]. While in determining the lignin content of each pulp sample, method from TAPPI T 22 os-74 procedure was used. After pulping process, fiber analysis in terms of length after pulping process was determined using a fiber analyser (model Sherwood INST FAS-3000).

\section{B. Handsheet Formation}

Then, handsheet of the pulp after treatment was formed using pulp stock with consistency of $0.3 \%$. The stock was prepared by using $24 \mathrm{~g}$ of oven dry weight pulp and was diluted with $8 \mathrm{~L}$ of distilled water in disintegrator at 15,000 revolutions per minute. The formation of handsheet was started by pouring $400 \mathrm{~mL}$ of stock solution into a handsheet machine tank. Water was filled in the tank and aerated to disperse the pulp. Then the water was drained, and the remained pulp formed handsheet on a mesh plate. The wet handsheet was pressed using a roller and was let to be dried under room condition $\left(20^{\circ} \mathrm{C}\right)$ for one night. The dried handsheet was then prepared to cross-linking process.

\section{Crosslinking Process}

In cross-linking process, 5 g of citric acid powder and 100 $\mathrm{mL}$ of distilled water were used. Citric acid and distilled water were mixed to $5 \%$ consistency solution in a beaker. The solution was stirred continuously until citric acid was fully dissolved. The citric acid solution was applied to the dried handsheet using pressurised spray until fully wetted about 50 $\mathrm{ml}$. Then, the dried handsheet which was applied with citric acid was let to dry in a conditioned room $\left(20^{\circ} \mathrm{C}\right)$ for 24 hours. As drying process completed, the samples were heated for 30 minutes in an oven at $145^{\circ} \mathrm{C}$ and later formed cross-linked handsheet. The cross-linked handsheet was then cut into strips $(1.5 \mathrm{~cm}$ width with length $9 \mathrm{~cm})$. All strips were dipped into a glass of test tube containing distilled water (about $1 \mathrm{~cm}$ dipped) for capillary measurement test. Time and duration were taken as the water travelled and passed through the strips was recorded.

TABLE I: CHEMICAL COMPOSITION OF UNMODIFIED EFB AND TREATED

\begin{tabular}{cllc}
\hline $\begin{array}{l}\text { Sample } \\
\text { code }\end{array}$ & Treatment Conditions & $\begin{array}{l}\text { Extractives } \\
(\%)\end{array}$ & $\begin{array}{l}\text { Hemicellulose } \\
(\%)\end{array}$ \\
\hline A & Unmodified sample & $4.00 \%$ & $23.25 \%$ \\
B & Pre-hydrolysis 20 min & $14.40 \%$ & $14.35 \%$ \\
C & Pre-hydrolysis 40 min & $15.20 \%$ & $9.19 \%$ \\
D & Pre-hydrolysis 60 min & $19.20 \%$ & $4.73 \%$ \\
E & Pre-hydrolysis 80 min & $22.00 \%$ & $3.75 \%$ \\
\hline
\end{tabular}

TABLE II: CHEMICAL COMPOSITION OF UNMODIFIED EFB AND TREATED

\begin{tabular}{clc} 
& \multicolumn{2}{c}{ EFB USING ALKALI TREATMENT } \\
\hline & Treatment Conditions & Lignin Content (\%) \\
\hline $\mathrm{A}$ & Unmodified sample & $15.14 \%$ \\
$\mathrm{~B}$ & $17 \% \mathrm{NaOH}$ & $10.42 \%$ \\
$\mathrm{C}$ & $22 \% \mathrm{NaOH}$ & $6.28 \%$ \\
$\mathrm{D}$ & $27 \% \mathrm{NaOH}$ & $4.66 \%$ \\
$\mathrm{E}$ & $32 \% \mathrm{NaOH}$ & $1.13 \%$ \\
\hline
\end{tabular}

\section{Results And Discussions}

\section{A. Chemical Composition}

The chemical composition of EFB fibers after pre-hydrolysis is shown in Table I. Sample A was unmodified fiber which was used as a control variable, while Sample B, C, $\mathrm{D}$ and $\mathrm{E}$ were treated with different conditions. From this study, it was found that the amount of extractives being removed out was increased with the increasing of time, while the hemicellulose content was decreased. This was due to the composition of hemicellulose was taken over by extractives and other components. For the longest residence time of pre-hydrolysis, the hemicellulose content was dropped to $3.75 \%$ which was $83.87 \%$ loss from the original 
hemicellulose content. However, hemicellulose removal did not manage to reach $100 \%$ even after 80 min due to bonding of stable hemicellulose to the cellulose fibrils [8]. During alkali treatment, results showed that the lignin content was reduced when high concentration of alkali charge was used (Table II). The highest alkali charge which was $32 \%$ of sodium hydroxide $(\mathrm{NaOH})$ removed about $92.53 \%$ of lignin in cellulose fibrils, with remaining residue attached to the fibers. This was due to a strong carbon-carbon linkage and the presence of aromatic groups which were very resistant to chemical attack which prevented the degradation of lignin in fiber [8]. However, if higher alkali charge was used, it may trigger the carbohydrate degradation and damaging the fibers [19].

\section{B. Influence of Chemical Composition of Cross-lined EFB Fiber on Their Capillarity}

Fig. 1 illustrates rate of water absorption of cross-linked EFB fibers after treatment. The treatment conditions for Sample B was (20 min for pre-hydrolysis, $17 \% \mathrm{NaOH}$ for pulping), followed by Sample C (40 min pre-hydrolysis, 22\% $\mathrm{NaOH}$ pulping), Sample D (60 min pre-hydrolysis, $27 \%$ $\mathrm{NaOH}$ pulping) and Sample E (80 min pre-hydrolysis, 32\% $\mathrm{NaOH}$ pulping). From the results in Fig. 1, it can be seen that the rate of water absorption of cross-linked EFB fibers increased with increasing pre-hydrolysis time and high alkali charge during pulping process. The increasing rate for Sample B, C and D was affected by for pre-hydrolysis time. Previous studies reported that, the rate of water absorption into fibers was affected from porosity and capillaries. As more hemicellulose was removed, the capillary spaces in fibers become bigger, and the fiber network became less dense [8].

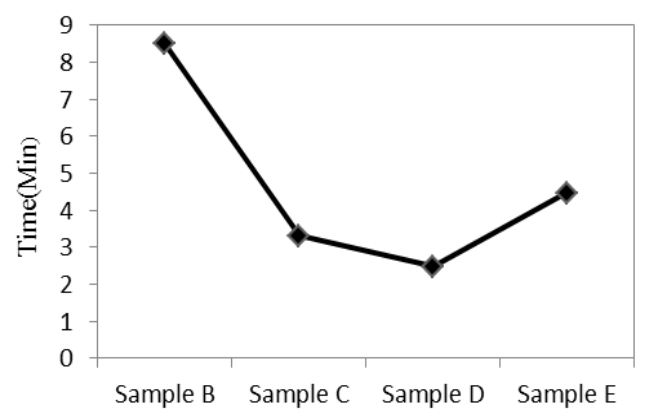

Fig. 1. Rate of water absorption of cross-linked EFB fibers after treatment.

These physical changes contributed to a better fiber arrangement. The less compact fiber network was able to enhance the water molecules to travel along its capillary cavity. However, the change in Sample E was affected by lignin content in the fiber. The lignin was the component in fiber that acted as matrix for connecting cellulose and hemicellulose [20]. It could be related to Sample B, C, and D which by removing the lignin, the blockage was also removed and producing a high porosity in fiber. This factor also would allow the water molecules to transfer along the paper strips in short time without much resistance. However, in Sample E, the progressive lignin removal was too critical which it reduced the porosity and formed a compact structure in fiber network. Thus the passage for water molecule to travel along the fiber cavities became narrow.

Table III shows fiber length of EFB fibers after chemical treatments. Results showed that the length of fiber was reduced with increasing pre-hydrolysis time and increasing amount of alkali charge used during pulping. Based on the results, Sample E had the shortest fiber length as compared to others. This was due to the concentration of $\mathrm{NaOH}$ used in Sample E (32\%) which was the highest. The fiber would be fibrillated more but at the same time it underwent cellulose degradation, that made the fiber shorter [19], [21]. The short fibers were able to form more fiber bonding in network that led to high density paper, while long fibers tend to entangle between them, and became more porous due to less fiber bonding. In relation to the rate of water absorption, the short fibers in Sample E formed a compact and high density paper which made it slower due to reduction of its porosity. Thus, water molecules needed longer time to travel along the fiber network of the cross-linked EFB fibers.

\begin{tabular}{lll}
\multicolumn{2}{l}{ TABLE III: LENGTH OF EFB FIBER AFTER CHEMICAL TREATMENTS } \\
\hline $\begin{array}{l}\text { Type of } \\
\text { samples }\end{array}$ & Rate of water absorption (min) & $\begin{array}{l}\text { Fiber Length } \\
(\mathrm{mm})\end{array}$ \\
\hline Sample B & 20 min prehydrolysis/ 17\% NaOH & 0.78 \\
Sample C & 40 min prehydrolysis/ 22\% NaOH & 0.72 \\
Sample D & 60 min prehydrolysis/ 27\% NaOH & 0.70 \\
Sample E & 80 min prehydrolysis/ 32\% NaOH & 0.64 \\
\hline
\end{tabular}

Fig. 2 shows the rate of speed of water absorption according to length of handsheet strips. Results showed that the speed of absorption of the paper strips did not uniform and turned to slow down from $1 \mathrm{~cm}$ to $9 \mathrm{~cm}$ length. The increasing speed water absorption was due to capillaries and porosity of paper. Large capillary spaces and high porosity of the fiber increased the rate of speed water absorption. However, due to high content of amorphous structure in EFB fiber, the dimensional stability had caused swelling in the fiber [9]. The swelling later reduced capillary spaces and closed the pore structure of the fibers. The fiber network became narrow which increased the difficulty of water molecule to pass along the handsheet strips. Thus, the rate of speed absorption reduced.

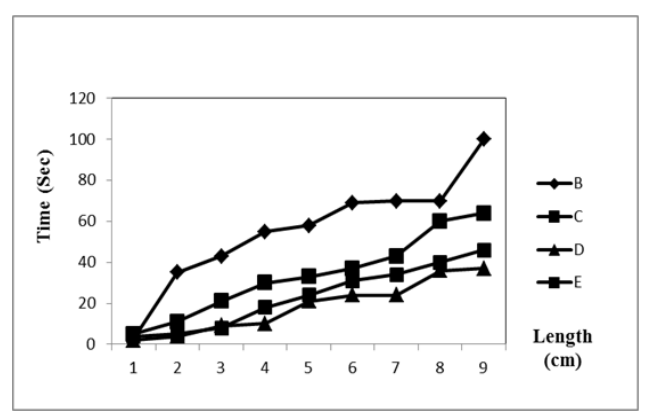

Fig. 2. Rate of speed water absorption according to length of paper strips.

\section{Effect of Hemicellulose and Lignin Removal on Moisture Sorption and Water Absorption}

Table IV shows the moisture sorption and water absorption test on EFB handsheet. The result showed that with the increase of pre-hydrolysis time and high concentration of 
$\mathrm{NaOH}$ during pulping, the percentage for water absorption and moisture sorption was increased from Sample B to Sample D. Extensive removal of hemicellulose led to modification of the fiber structures properties. The fiber became more hydrophilic and less dense due to the lignin removal. The large capillary network had allowed the water or moisture to penetrate inside the fiber network without resistance. Furthermore, the extensive lignin removal had resulted in the increase of the fiber porosity which led to increase of the amount of moisture and water absorbed. During delignification of fiber, the pore structure was produce and located between cellulose and hemicellulose, previously occupied by lignin acted as coupling agent [22]. As the alkali charge was increased, the porosity was also increased. However, the result in Sample E showed that continuous lignin removal had reduced the amount of moisture and water absorption. Based on the results, it showed that $60 \mathrm{~min}$ of pre-hydrolysis time and $27 \% \mathrm{NaOH}$ were the optimum conditions of EFB fibers in this study The removal of lignin was able to increase the pore volume at first, but extensively delignification led to collapse of the cavities, lowering the amount of the pores [23]. It might probably the small pores that turned into large one had collapsed. High amount of alkali treatment led to fiber damage which decreased the ability of fibers to retain moisture and water [24].

TABLE IV: MOISTURE SORPTION AND WATER ABSORPTION TEST ON EFB HANDSHEET

\begin{tabular}{ccc}
\hline Samples & Water Absorption & Moisture Sorption \\
Code & & \\
\hline Sample B & $441 \%$ & $9.89 \%$ \\
Sample C & $445 \%$ & $11.30 \%$ \\
Sample D & $494 \%$ & $12.97 \%$ \\
Sample E & $450 \%$ & $11.44 \%$ \\
\hline
\end{tabular}

\section{CONCLUSIONS}

In this study, chemical composition of EFB fibers using pre-hydrolysis and alkali treatment was carried out. From the study, it can be concluded that:

- The amount of extractives becomes increased with the increasing of pre-hydrolysis time, while the hemicelluloses content decreased.

- Lignin content reduced when high concentration of alkali charge used.

- The capillary size increased with pre-hydrolysis treatment, while the alkali treatment has increase the porosity of fiber. However, the progressive of using alkali charge affected in reducing the fiber length which made the fiber network became compact.

- The rate of speed water absorption increased by removing lignin and hemicelluloses. The progressive removal of hemicelluloses and lignin influenced the water absorption and moisture sorption properties of EFB fiber.

- Hemicellulose removal improved the capillary spaces in fibers, while lignin removal increased the porosity of the fibers. However, the high content of amorphous structure in the fiber had affected fiber swelling which reduced the rate of speed water absorption.

\section{ACKNOWLEDGMENT}

This study was fully supported by Sciencefund Grant, Ministry of Science Technology and Innovation (MOSTI) Malaysia with the account number of 305/PTEKIND/613330.

\section{REFERENCES}

[1] S. Suganuma, et al., "Hydrolysis of cellulose by amorphous carbon bearing $\mathrm{SO}_{3} \mathrm{H}, \mathrm{COOH}$, and $\mathrm{OH}$ groups," Journal of the American Chemical Society, vol. 130, no. 38, pp. 12787-12793, 2008.

[2] I. Siró and D. Plackett, "Microfibrillated cellulose and new nanocomposite materials: A review,” Cellulose, vol. 17, no. 3, pp. 459-494, 2010.

[3] J. I. Morán, et al., "Extraction of cellulose and preparation of nanocellulose from sisal fibers, ” Cellulose, vol. 15, no. 1, pp. 149-159, 2008.

[4] A. C. O'sullivan, "Cellulose: the structure slowly unravels," Cellulose, vol. 4, no. 3, pp. 173-207, 1997.

[5] I. Y. A. Fatah, et al., "Exploration of a chemo-mechanical technique for the isolation of nanofibrillated cellulosic fiber from oil palm empty fruit bunch as a reinforcing agent in composites materials," Polymers, vol. 6, no. 10, pp. 2611-2624, 2014.

[6] D. Bondeson, A. Mathew, and K. Oksman, "Optimization of the isolation of nanocrystals from microcrystalline cellulose by acid hydrolysis," Cellulose, vol. 13, no. 2, pp. 171-180, 2006.

[7] X. M. Dong, J. F. Revol, and D. G. Gray, "Effect of microcrystallite preparation conditions on the formation of colloid crystals of cellulose," Cellulose, vol. 5, no. 1, pp. 19-32, 1998.

[8] B. M. Pejic, et al., "The effects of hemicelluloses and lignin removal on water uptake behavior of hemp fibers,” Bioresource Technology, vol. 99, no. 15, pp. 7152-7159, 2008

[9] K. L. Spence, et al., "The effect of chemical composition on microfibrillar cellulose films from wood pulps: Mechanical processing and physical properties,” Bioresource Technology, vol. 101, no. 15, pp. 5961-5968, 2010.

[10] L. Y. Mwaikambo and M. P. Ansell, "Chemical modification of hemp, sisal, jute, and kapok fibers by alkalization,” Journal of Applied Polymer Science, vol. 84, no. 12, pp. 2222-2234, 2002.

[11] C. P. Leh, et al., "Optimisation of oxygen delignification in production of totally chlorine-free cellulose pulps from oil palm empty fruit bunch fibre,” Industrial Crops and Products, vol. 28, no. 3, pp. 260-267, 2008.

[12] S. Shamsudin, et al., "Effect of steam pretreatment on oil palm empty fruit bunch for the production of sugars,” Biomass and Bioenergy, vol. 36, pp. 280-288, 2012.

[13] W. E. Kaar, C. V. Gutierrez, and C. M. Kinoshita, "Steam explosion of sugarcane bagasse as a pretreatment for conversion to ethanol," Biomass and Bioenergy, vol. 14, no. 3, pp. 277-287, 1998.

[14] W. R. W. Daud, K. A. Wahid, and K. N. Law, "Cold soda pulping of oil palm empty fruit bunch (OPEFB),” Bioresources, vol. 8, no. 4, pp. 6151-6160, 2013.

[15] K. Wong, et al., "Wicking properties of linen treated with low temperature plasma,” Textile Research Journal, vol. 71, no. 1, pp. 49-56, 2001.

[16] J. Thomas, et al., "Capillary water provision system for irrigation," International Journal of Information Science and Computing, vol. 2, no. 1, pp. 13-20, 2015.

[17] Y. Tan and M. Guo, "Using surface free energy method to study the cohesion and adhesion of asphalt mastic," Construction and Building Materials, vol. 47, pp. 254-260, 2013.

[18] L. E. Wise, "Chlorite holocellulose, its fractionation and bearing on summative wood analysis and on studies on the hemicelluloses," Paper Trade, vol. 122, pp. 35-43, 1946.

[19] N. H. Shin and B. Strömberg, "Impact of cooking conditions on pulp yield and other parameters,” in Colóquio Internacional sobre Celulose Kraft de Eucalipto, 2003, pp. 59-67.

[20] H. Chen, "Chemical composition and structure of natural lignocellulose,” in Biotechnology of lignocellulose, Springer, pp. 25-71, 2014.

[21] M. L. Troedec, et al., "Influence of various chemical treatments on the composition and structure of hemp fibres," Composites Part A: Applied Science and Manufacturing, vol. 39, no. 3, pp. 514-522, 2008.

[22] A. Scallan and A. Tigerström, "Swelling and elasticity of the cell walls of pulp fibres,” Journal of Pulp and Paper Science, vol. 18, no. 5, pp. J188-J193, 1992.

[23] L. Salmén and J. Berthold, “The swelling ability of pulp fibres,” Fundamentals of Papermaking, pp. 683-701, 1997. 
[24] I. Rauvanto, The Effect of Oxygen Delignification on Fiber Properties in Kraft Pulp Production-a Review, Julkaisu/Report-Lappeenrannan teknillinen yliopisto, Kemiantekniikan osasto, 2003.

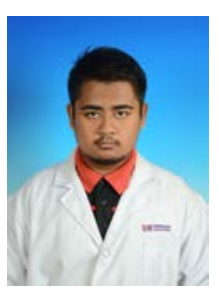

Mohammad Aliff Shakir is a master student from School of Industrial Technology, Universiti Sains Malaysia. His major focus is in chemical modification of fibers, composite materials and application of polymer. He has been awarded a silver medal in Novel Research and Innovation Competition (NRIC) in 2015.

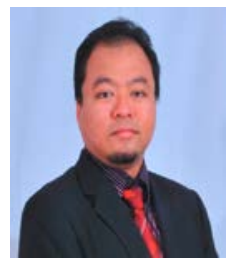

Mohd Firdaus bin Yhaya obtained his $\mathrm{PhD}$ from University of New South Wales, Australia. He is currently a senior lecturer in School of Industrial Technology, Universiti Sains Malaysia. His research interests are in angstromtechnology, coatings chemistry and technology, click chemistry, and green chemistry.

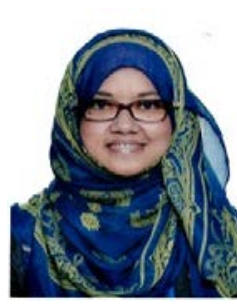

Mardiana Idayu Ahmad earned her $\mathrm{PhD}$ in sustainable energy technologies from the University of Nottingham, UK in 2011. She is a member of Institution of Engineering \& Technology (IET) UK and World Society of Sustainable Energy Technologies (WSSET). Her primary research interests include renewable \& sustainable energy technologies, IAQ and building ventilation, environmental management and risk assessment. 